\title{
ranchen \\ Geotechnical Engineering Perspectives: Challenges and Solutions in the Transition to a Post-Lignite Era ${ }^{\dagger}$
}

\author{
Ioannis E. Zevgolis ${ }^{1, *(\mathbb{D})}$, Alexandros I. Theocharis ${ }^{2}$ and Nikolaos C. Koukouzas ${ }^{2}$ \\ 1 School of Mining and Metallurgical Engineering, National Technical University of Athens, \\ 15773 Athens, Greece \\ 2 Centre for Research \& Technology Hellas, Chemical Process \& Energy Resources Institute, \\ 15125 Athens, Greece; theocharis@certh.gr (A.I.T.); koukouzas@certh.gr (N.C.K.) \\ * Correspondence: izevgolis@metal.ntua.gr \\ + Presented at International Conference on Raw Materials and Circular Economy, Athens, Greece, \\ 5-9 September 2021.
}

\begin{abstract}
Coal and lignite regions are on the way to reinvent themselves. In this work, three aspects related to the reclamation and exploitation of these mining areas are analyzed, focusing on the role of geotechnical engineering. Firstly, the slope stability of lignite excavations is examined during the water filling reclamation practice. Secondly, the effect of extreme rainfall is studied on the slope stability of abandoned lignite mines. Finally, aspects of the potential reclamation of a waste dump by a highway or a railroad are investigated. Overall, the three studies underline the importance of geotechnical engineering in the transition to a post-lignite era.
\end{abstract}

Keywords: abandoned mines; mine reclamation; surface mines; geotechnics; slope stability; Green Deal

Citation: Zevgolis, I.E.;

Theocharis, A.I.; Koukouzas, N.C. Geotechnical Engineering Perspectives: Challenges and Solutions in the Transition to a Post-Lignite Era. Mater. Proc. 2021, 5 , 17. https://doi.org/10.3390/ materproc2021005017

Academic Editor: Evangelos Tzamos

Published: 17 November 2021

Publisher's Note: MDPI stays neutral with regard to jurisdictional claims in published maps and institutional affiliations.

Copyright: (c) 2021 by the authors. Licensee MDPI, Basel, Switzerland. This article is an open access article distributed under the terms and conditions of the Creative Commons Attribution (CC BY) license (https:// creativecommons.org/licenses/by/ $4.0 /)$.

\section{Introduction}

For many decades, coal and lignite mining has been a vital industry based on the extraction of non-renewable coal resources from the ground. However, the decisions for decarbonization and the transition to a low-carbon economy have led to mine closures in several regions across Europe and globally. With this shift in the energy structure and the groundbreaking changes in the economy, the economic and social impact in coal regions should not be ignored. Decarbonizing these areas will leave vast abandoned mines and waste dumps that burden local and national communities, unless they are suitably reclaimed.

Coal regions on the verge of a post-coal era are searching for ways to reinvent themselves. Several solutions have been proposed for this transition, and some have been implemented, including reclamation of coal areas by renewable energy systems (e.g., wind farms and solar parks) and the development of recreational areas with open-pit lakes and green zones. However, these plans pose geotechnical challenges that relate to the safety and cost-efficiency of the proposed solutions. Furthermore, climate change should be considered towards this new era, as temperature, rainfall, and wind speed changes might crucially affect the areas' safety.

In this work, three issues are analyzed regarding the role of geotechnical engineering in the reclamation of lignite mines and adjacent waste dumps. Firstly, the slope stability of lignite excavations is examined when filling the excavation with water to create an open-pit lake. Secondly, the effect of extreme rainfall is studied on the slope stability of abandoned lignite mines. Specifically, the rainfall characteristics are incorporated in a numerical analysis to examine its influence on the safety factor of partially saturated slopes of a lignite excavation. Finally, the potential reclamation presented by a case study waste dump is investigated. Two different scenarios were preliminary analyzed, i.e., the foundation of a highway or a railroad, based on the waste material's soil properties. 
Overall, the three studies underline the importance of geotechnical engineering in the transition to a post-lignite era. Each of the three cases presents a different aspect ranging from reclamation of lignite excavations with open-pit lakes to the reclamation of waste dumps and the safety of the areas due to the effect of climate change.

\section{Slope Stability of Open-Pit Excavations during Water Filling}

The sustainable use of open-pit mine excavations is a major issue globally, with one of the most common practices of reclamation being the formation of pit lakes. During this process, closed mines are filled with water to create a lake, typically offered to the local societies for recreational purposes. As mining activity has been linked with several failure events [1], the geotechnical problems could be significant, and slope stability may not be guaranteed in the case of water filling. There have already been cases of small pit lakes, and some have encountered severe geotechnical problems. The present work examines these stability issues through a numerical analysis and, particularly, the finite element method (FEM) combined with the shear strength reduction (SSR) technique [2].

In surface lignite mines, the open-pit would often be partially backfilled with spoil dump materials during mining procedures. This case is examined in this paper, identifying a simplified homogeneous slope at the mine edge overlying a bedrock-type formation of high stiffness and strength at the excavation bottom (Figure 1). It is worth noticing that this slope presents a typical case of lignite excavations [3,4]. The initial groundwater table is defined by a steady-state flow between two boundary limits, one at the toe of the excavation and the other ten meters below the left boundary of the model. The lake filling of $100 \mathrm{~m}$ was simulated in ten stages, filling $10 \mathrm{~m}$ in each stage. Simultaneously, for each stage, the left boundary, representing the groundwater evolution in the slope, rose $1 \mathrm{~m}$. As a result, the lake is full after the last filling stage, and the groundwater is at the ground's surface. The SSR technique was carried out at each stage to obtain the safety factor (SF), and a Mohr-Coulomb model was employed for all materials.

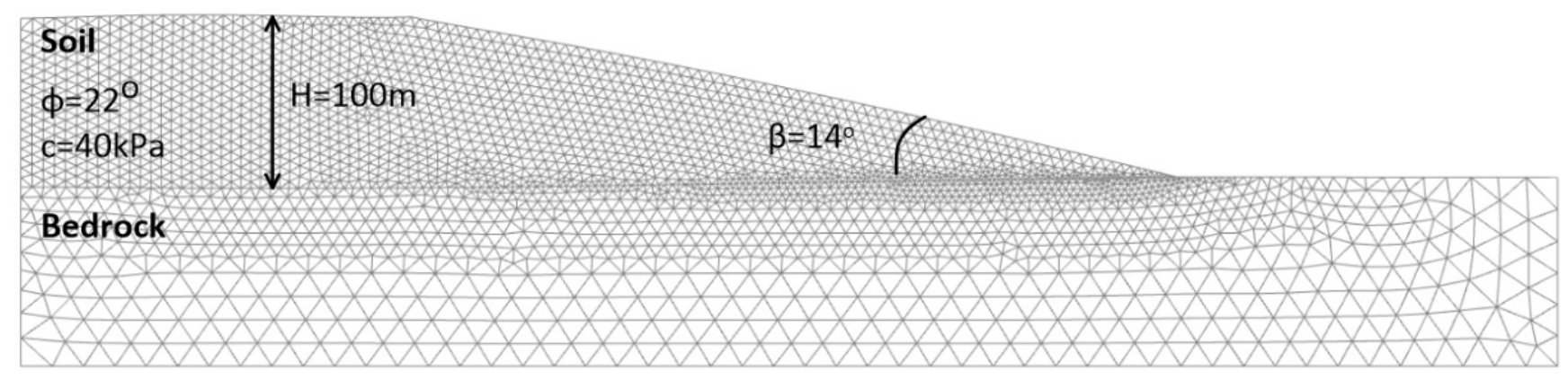

Figure 1. Finite element discretization and the main characteristics of open-pit slope.

Figure 2a presents the SF with the filling percentage. During the first three stages, the SF is less than the initial one, reaching a minimum at about $20 \%$ of the filling height. Furthermore, to quantify the probability of failure of the slope during water filling, the shear strength - through the parameters $\varphi^{\prime}$ and $c^{\prime}$ - was considered to have a low-to-medium uncertainty. In that vein, $\varphi^{\prime}$ was assumed to be a $10 \%$ coefficient of variation (COV) and $c^{\prime}$ to be $20 \%$. The point estimate method [5] was used and a normal distribution was assumed for the performance factor (in this paper, the safety factor), assuming symmetric distributions for both parameters. Figure $2 \mathrm{~b}$ presents the evolution of the probability of failure $\left(\mathrm{P}_{\mathrm{F}}\right)$ with the filling percentage. The evolution is similar, but reversed to the $\mathrm{SF}$; the $P_{F}$ increases to a maximum until $20 \%$ of the filling height and decreases to very low values as the lake fills to its maximum. The increase is more apparent in terms of $P_{F}$ (than the decrease in the SF) as it increases from $2 \times 10^{-4}$ to $10^{-3}$, a significant increase in the risk level. 

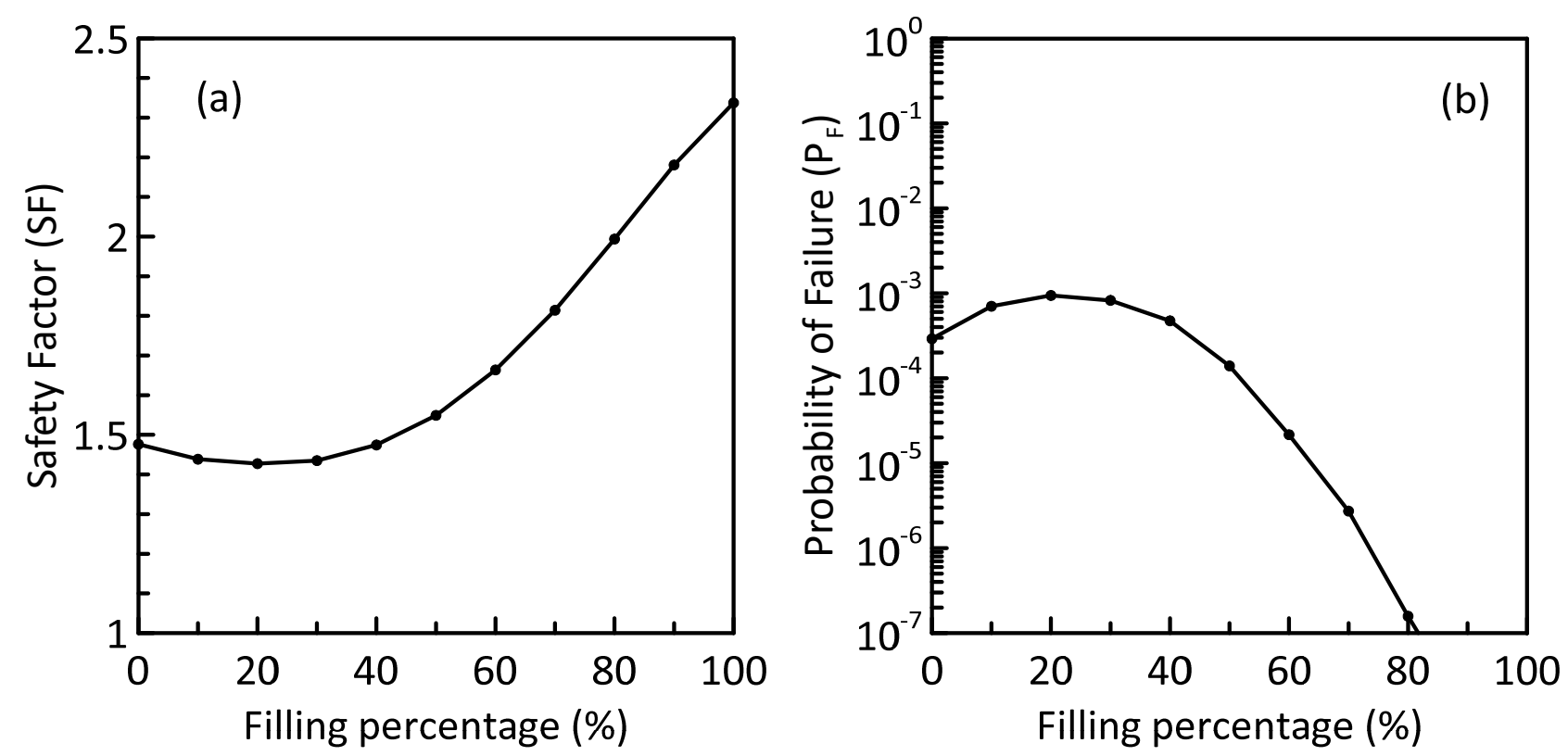

Figure 2. Evolution of (a) the safety factor and (b) the probability of failure with the filling percentage of a flooding open-pit.

Overall, at the first stages of the lake filling process, an SF decrease and a $\mathrm{P}_{\mathrm{F}}$ increase are observed. However, as the lake keeps filling, the SF becomes larger than the initial one and the $\mathrm{P}_{\mathrm{F}}$ smaller. This particular case's minimum SF (and maximum PF) is at $20 \%$ of the total filling height. Further research by the authors will consider laboratory data of spoil material to refine the soil properties and incorporate more complicated stratigraphy and water conditions.

\section{Rainfall Effect on Slope Stability of Abandoned Lignite Mines}

Intense rainfall and extreme weather events are often associated with landslides and catastrophes on natural or engineered slopes. The influence of rainfall on open-pit coal and lignite mines' slope stability has long been identified and considered for design purposes [6,7]. In this work, a typical slope representing a mine excavation is simulated under an extreme rainfall event of $6 \mathrm{~mm} / \mathrm{h}$ for two days $(48 \mathrm{~h})$. The Finite Element Method (FEM) is employed, and a fully coupled flow-deformation analysis is conducted that allows for the simultaneous evaluation of the unsaturated transient seepage flow and soil's mechanical response. Similar slope geometry and soil properties as in the previous section are used; only the height, in this case, is $150 \mathrm{~m}$, higher than the previous one. Furthermore, for the unsaturated zone, a form of the widely known van Genuchten-Mualem model $[8,9]$ is used with $\mathrm{g}_{\mathrm{a}}=0.01 \mathrm{~m}^{-1}, \mathrm{~g}_{\mathrm{n}}=1.3, \mathrm{~g}_{1}=0.5$, and $\mathrm{S}_{\mathrm{r}}=0.2$; the saturated soil permeability is $\mathrm{k}_{\mathrm{s}}=1.67 \times 10^{-4} \mathrm{~cm} / \mathrm{s}$.

The FEM is combined (as in the previous section) with the shear strength reduction (SSR) technique [2], and the safety factor (SF) is calculated every 0.25 days $(6 \mathrm{~h})$. Figure 3a presents the evolution of the $\mathrm{SF}$ as the rainfall infiltrates the slope. As the rainfall infiltrates the slope, suction decreases, and the groundwater level changes; thus, the SF decreases in a non-linear way from 1.4 to 1.15. Therefore, during this rainfall event, a significant SF decrease is observed. Moreover, similarly to the previous section, the shear strength parameters are considered random variables with a low to medium COV, and the point estimate method with a normal distribution for the SF is employed to obtain the probability of failure. Therefore, $\varphi^{\prime}$ was assumed to have a $10 \%$ COV and $c^{\prime}$ to have $20 \%$. Figure $3 \mathrm{~b}$ presents the evolution of the $\mathrm{P}_{\mathrm{F}}$ as the rainfall infiltrates the slope. The risk level represented by the $\mathrm{P}_{\mathrm{F}}$ increases drastically during the rainfall; $\mathrm{P}_{\mathrm{F}}$ increases from $2 \times 10^{-3}$ to over $10^{-1}$ after the two days of heavy rainfall. Overall, as the rainfall event proceeds, an $\mathrm{SF}$ decrease and a $\mathrm{P}_{\mathrm{F}}$ increase are observed. This case's minimum SF and maximum PF are 
at the end of the rainfall event and equal to 1.15 and $10^{-1}$, respectively. Further research will consider laboratory data of spoil material for the soil properties and incorporate more complicated stratigraphy and water conditions and even the spatial variability of the critical geotechnical parameters.
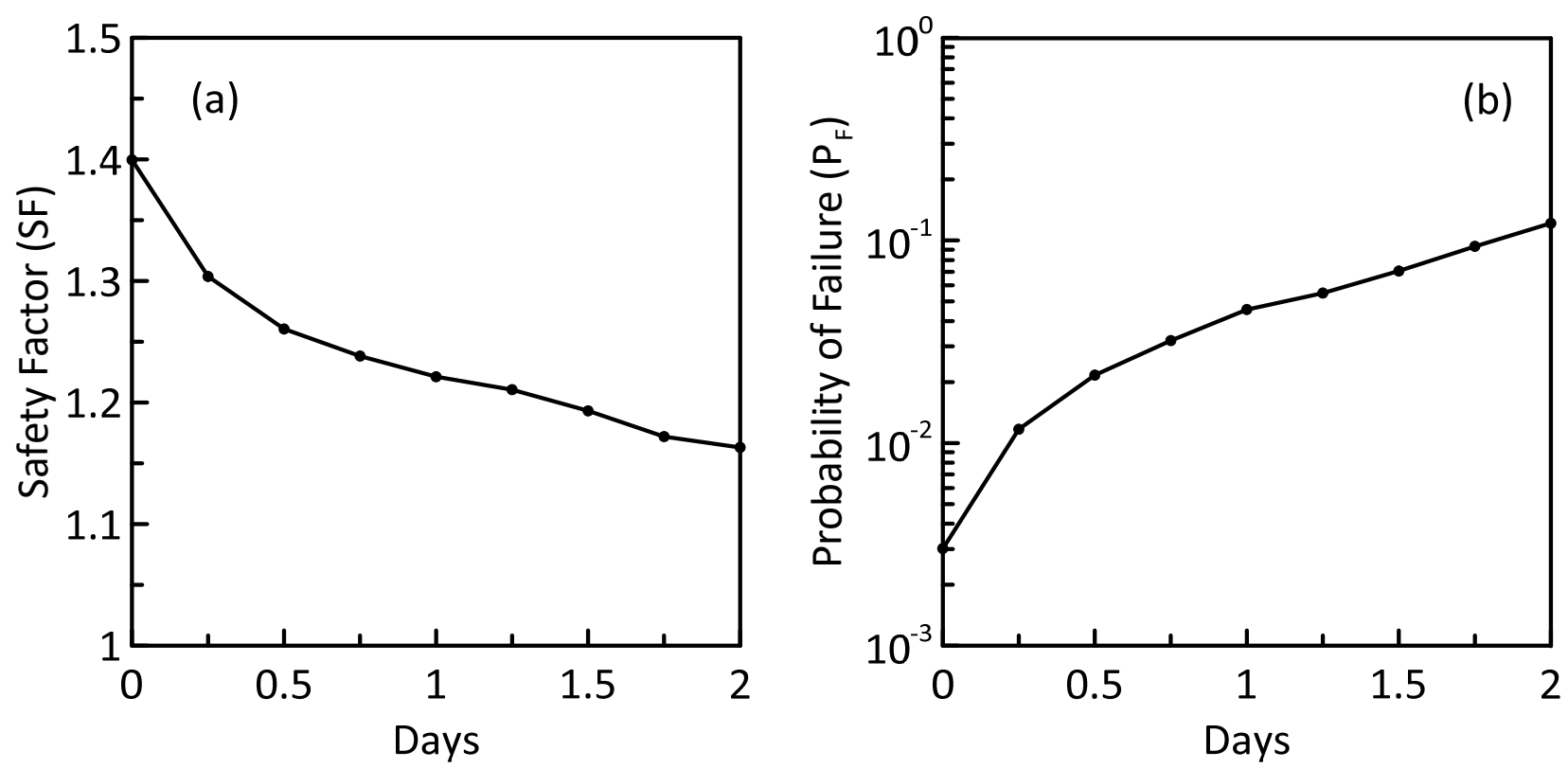

Figure 3. Evolution of (a) the safety factor and (b) the probability of failure of an open-pit slope during rainfall.

\section{Reclamation of a Lignite Waste Dump by a Highway or a Railroad}

The Soulou spoil heap is in the Ptolemais area and consists of sterile materials excavated from two adjacent lignite mines: the Kardia mine and the South Field mine. Ground profiles in the excavations of the Kardia and South Field mines consisted of a thick overburden zone of sterile that overlay the exploitable lignite deposits. The sterile material primarily consists of marls and clays and occasionally of weak conglomerates and water-bearing sands.

The Soulou spoil heap is about $5 \mathrm{~km}$ long, $0.4-2.1 \mathrm{~km}$ wide at its top, $1.8-3.65 \mathrm{~km}$ wide at its base, and 150-170 $\mathrm{m}$ in height. The construction methods and the material suggest the nearly chaotic nature of the soil mix, a claim verified by results of laboratory tests. Therefore, a systematic effort was made to classify and characterize the spoil material, quantifying its geotechnical properties, uncertainty, and contrasting results with typical soils [10]. Due to the extraction and deposition processes, the spoil heap's body is highly heterogeneous, leading to the spoil mass's consideration as one unified spoil material with significant uncertainty. The characteristic material within the spoil heap was identified as an intermediate material classified as high plasticity silt with low elastic properties, i.e., Young's modulus $\mathrm{E} \approx 2-10 \mathrm{MPa}$.

Due to its low elastic properties, the spoil material does not meet the minimum requirements of Greek, European, or American standards to design a highway or a railroad using it as a subgrade. In addition, geotechnical uncertainties pose a significant obstacle to the safety of the design. Therefore, ground improvement techniques are necessary.

\section{Conclusions}

In this work, three geotechnical subjects were presented regarding the reclamation of lignite mines and adjacent waste dumps. Firstly, the slope stability of lignite excavations was investigated when filling the open-pit with water. Secondly, the effect of an extreme rainfall event was studied on the stability of a lignite excavation's slope. Lastly, a 
preliminary analysis was briefly discussed for the potential reclamation of a waste dump by a highway or a railroad. In these three different cases, the importance of geotechnical engineering is suggested towards the transition to a post-lignite era, and each of the three cases presents a different aspect of this transition.

For the water filling case, an SF decrease and a $P_{F}$ increase were observed at the initial stages. However, as the lake keeps filling, the SF becomes larger and the $\mathrm{P}_{\mathrm{F}}$ smaller. That means that, based on the assumptions, the most dangerous conditions for the slope stability are at the initial stages of the lake filling; afterwards, the more the lake is filled, the more stable it becomes. This particular case's minimum SF (and maximum $P_{F}$ ) is at $20 \%$ of the total filling and are 1.45 (and $10^{-3}$ ).

For the rainfall analysis, an SF decrease and a $P_{F}$ increase were observed as the rain proceeded. This case's minimum SF and maximum $\mathrm{P}_{\mathrm{F}}$ were, as expected, at the end of the rainfall and equal to 1.15 and $10^{-1}$, respectively. The heavy rain with a considerable duration (2 days) severely decreases the SF and obtains a very safe slope close to failure. Although the SF remains 1.15 , appearing adequate, the significant $P_{F}$ value $(10 \%)$ declares a high risk level.

Finally, the soft spoil material analyzed in [10] and used as a reference for potential reclamation cannot support a highway or a railroad due to its low elastic moduli. Ground improvement techniques are necessary, and a special geotechnical study is required.

Author Contributions: Conceptualization, I.E.Z.; methodology, I.E.Z.; software, A.I.T.; validation, I.E.Z., A.I.T.; writing—original draft preparation, A.I.T.; writing—review and editing, I.E.Z., A.I.T. and N.C.K. All authors have read and agreed to the published version of the manuscript.

Funding: This research was funded by the European Union's Research Fund for Coal and Steel, under the projects RAFF grant agreement No. 847299, TEXMIN grant agreement No. 847250, and SUMAD grant agreement No. 847227.

Conflicts of Interest: The authors declare no conflict of interest. The funders had no role in the design of the study; in the collection, analyses, or interpretation of data; in the writing of the manuscript; or in the decision to publish the results.

\section{References}

1. Zevgolis, I.E.; Deliveris, A.V.; Koukouzas, N.C. Slope failure incidents and other stability concerns in surface lignite mines in Greece. J. Sustain. Min. 2019, 18, 182-197. [CrossRef]

2. Plaxis, 2D Finite Element Geotechnical Analysis Software. 2020. Available online: https://www.bentley.com/en/products/ product-line/geotechnical-engineering-software/plaxis-2d (accessed on 1 April 2020).

3. Mikroutsikos, A.; Theocharis, A.I.; Koukouzas, N.C.; Zevgolis, I.E. Slope stability of deep surface coal mines in the presence of a weak zone. Géoméch. Geophys. Geo-Energy Geo-Resour. 2021, 7, 66. [CrossRef]

4. Theocharis, A.I.; Zevgolis, I.E.; Koukouzas, N.C. A comprehensive geotechnical characterization of overburden material from lignite mine excavations. Geomech. Geophys. Geo-Energy Geo-Resour. 2021, 7, 30. [CrossRef]

5. Rosenblueth, E. Point estimates for probability moments. Proc. Natl. Acad. Sci. USA 1975, 72, 3812-3814. [CrossRef] [PubMed]

6. Chowdhury, R.; Nguyen, V. Risk updating for rainfall-triggered spoil failures. In Proceedings of the International Symposium on Prediction and Performance in Geotechnical Engineering, Calgary, AB, Canada, 17-19 June 1987.

7. Kavvadas, M.; Marinos, P.; Anagnostopoulos, A. Stability of open-pit lignite slopes in Ptolemais, Greece, in Landslides. In Proceedings of the Landslides, International Symposium, Rotterdam, The Netherlands, 10-14 February 1992; pp. 1293-1298.

8. Mualem, Y. A new model for predicting the hydraulic conductivity of unsaturated porous media. Water Resour. Res. 1976, 12, 513-522. [CrossRef]

9. van Genuchten, M.T. A Closed-form equation for predicting the hydraulic conductivity of unsaturated soils. Soil Sci. Soc. Am. J. 1980, 44, 892-898. [CrossRef]

10. Zevgolis, I.E.; Theocharis, A.I.; Deliveris, A.V.; Koukouzas, N.C.; Roumpos, C.; Marshall, A.M. Geotechnical characterization of fine-grained spoil material from surface coal mines. J. Geotech. Geoenviron. Eng. 2021, 147, 04021050. [CrossRef] 